\title{
Modul "Gen Positif" untuk Meningkatkan Pengetahuan Regulasi Emosi Takut Gagal Siswa Remaja Awal
}

\author{
Astiti Tenriawaru Ahmad ${ }^{1} \mathcal{E}$ Asmadi Alsa ${ }^{2}$ \\ Fakultas Psikologi Universitas Gadjah Mada
}

\begin{abstract}
Early adolescents need adaptation in various aspects including in the process of achievement of academic achievement. The difficulties encountered in achieving goals in the academic field caused early adolescents to develop a fear of failure. Individuals will try to avoid failure by determining their goals far below its potential, feel anxious, and not motivated in learning. This emotion can be a serious problem if it is not regulated in an adaptive way. Therefore early adolescents need knowledge of how to regulate the emotions of fear of failure. This study aims to validate the module "Gen Positif" (GENerasi teramPil mengOlah emoSI dan akTIF berprestasi) and find out how far the increase in knowledge and ability of emotional regulation of fear of failure in early adolescents. The study design used untreated control group designs with dependent pretest and posttest samples. Research participants as many as 12 early adolescents. The analysis of the study was conducted by comparing the scores of emotional regulation knowledge before and after manipulation was given. The results show that the module "Gen Positif" is valid content and empirical.
\end{abstract}

Keywords: early adolescents; emotional regulation training; emotion fear of failure

Abstrak. Siswa remaja awal membutuhkan adaptasi dalam berbagai aspek termasuk dalam proses pencapaian prestasi akademik. Kesulitan yang dihadapi dalam mencapai tujuan di bidang akademik menyebabkan siswa remaja awal mengembangkan perasaan takut gagal. Individu tersebut akan berusaha menghindari kegagalan dengan cara menentukan tujuan mereka jauh di bawah potensinya, merasa cemas, dan tidak termotivasi dalam belajar. Emosi ini dapat menjadi masalah serius jika tidak diregulasi dengan cara adaptif. Oleh karena itu para siswa remaja awal membutuhkan pengetahuan mengenai cara meregulasi emosi takut gagal. Berdasarkan hal tersebut, penelitian ini bertujuan memvalidasi modul "Gen Positif" (GENerasi teramPil mengOlah emoSI dan akTIF berprestasi) dan mengetahui sejauh mana peningkatan pengetahuan dan kemampuan regulasi emosi takut gagal pada siswa remaja awal. Desain penelitian menggunakan untreated control group designs with dependent pretest and posttest samples. Partisipan penelitian sebanyak 12 siswa remaja awal. Analisis penelitian dilakukan dengan membandingkan skor pengetahuan regulasi emosi sebelum dan sesudah manipulasi diberikan. Hasil penelitian menunjukkan bahwa modul "Gen Positif" valid secara konten dan empirik.

Kata kunci: siswa remaja awal; pelatihan regulasi emosi; emosi takut gagal

Ketakutan akan kegagalan adalah suatu

\footnotetext{
1 Korespondensi mengenai isi artikel ini dapat dilakukan melalui : astiti.tenriawaru@mail.ugm.ac.id

2 Atau melalui asmalsa@ugm.ac.id
}

penilaian terhadap ancaman yang diasosiasikan dengan konsekuensi aversive dari ketidakberhasilan mencapai tujuan yang diinginkan (Conroy, 2002; Sagar, 
Lavallee, \& Spray, 2007). Rasa takut akan kegagalan ini bisa dirasakan siapapun, salah satunya adalah siswa remaja. Siswa remaja awal yang berusia 12 - 15 tahun (Monks, Knoers, \& Haditono, 2001) cenderung merasa takut akan gagal disebabkan oleh kondisi akademik mereka. Hal tersebut dijelaskan oleh Li \& Zhang (2008), di mana ketakutan dan rasa cemas pada remaja lebih banyak disebabkan oleh kesulitan akademik. Michalcakova, Lacinova, Kyonkova, Bousa, \& Jelinek (2013) menambahkan bahwa kebanyakan rasa takut yang dialami remaja berusia 1113 tahun lebih banyak berhubungan dengan sekolah. Senada dengan pendapat tersebut, melalui survei awal yang telah dilakukan peneliti, data menunjukkan bahwa 54,11\% dari 85 siswa (usia 12 - 15 tahun) mengaku takut gagal dalam hal akademik.

Terdapat beberapa faktor yang membuat siswa remaja cenderung memiliki ketakutan akan gagal dalam hal akademik. Birney (Fried-Buchalter, 1997) menyatakan bahwa masyarakat masih sering menolak individu yang gagal meskipun sudah berusaha keras mencapai tujuannya. Kegagalan ini cenderung dijadikan sebuah label negatif oleh lingkungan. Sementara pada masa ini siswa remaja cenderung peka terhadap umpan balik dari lingkungan. Hal ini lah yang menurut Tyson, Linnenbrink, dan Hill (2009) menjadi alasan utama bagi siswa remaja awal mengembangkan perasaan takut akan kegagalan. Banyak kondisi di sekolah yang memunculkan umpan balik tersebut, seperti ujian, dan pemberian tugas yang melampaui batas kemampuan siswa, atau pun persaingan akademik di setiap siswa. Terlebih, pada saat remaja awal, individu mulai membandingkan dirinya dengan lingkungan sosial terkait dengan kemampuan mereka (Eccles, Wigfield, \& Schiefele, 1998). Label negatif yang diperoleh membuat siswa remaja khawatir menjadi tampak lebih buruk dibandingkan teman-temannya.

Selain itu, tingkat kesulitan pelajaran dan standar kelulusan yang semakin tinggi merupakan alasan semakin besarnya perasaan takut gagal pada siswa (Eccles, Eccles, Wigfield, \& Schiefele, 1998). Peningkatan penilaian ini akan mengancam tujuan siswa remaja awal dalam mencapai prestasi yang diharapkan. Sedangkan, remaja menganggap prestasi akademik merupakan hal yang penting untuk meramalkan keberhasilan di masa dewasa kelak (Handerson \& Dweck, 1990).

Terlebih Belanger, et al. (2013) mengatakan bahwa dampak dari kegagalan mengancam diri individu. Kegagalan membayangi individu sehingga timbul perasaan tidak aman setiap kali menemui peristiwa serupa. Terdapat banyak riset eksperimen kuasi yang menunjukkan bahwa sukses menuntun individu untuk meningkatkan prestasinya, sedangkan kegagalan cenderung menurunkan prestasi (Bandura, 1986; Diener \& Dweck, 1978). Oleh karena itu, individu termotivasi untuk menghindari kegagalan karena merasa khawatir dengan konsekuensi dari kegagalan tersebut. Konsekuensi dari kegagalan tersebut menurut Birney, Burdick, \& Teevan (1969), dipahami individu dari pengalaman dan pengamatan mereka yang pada akhirnya mengarahkan individu untuk menghindari kegagalan.

Sayangnya rasa takut akan kegagalan tersebut berdampak buruk pada siswa karena menimbulkan perasaan cemas, gelisah, sulit berkonsentrasi, performansi tidak maksimal, tidak semangat (motivasi beprestasi rendah), dan takut memulai sesuatu atau menyelesaikan sesuatu. Hal ini menunjukkan siswa merasa terganggu dengan emosi takut gagal yang dirasakan. 
Beberapa kasus yang ada menunjukkan dampak dari perasaan takut akan kegagalan, di antaranya berita yang dilansir oleh Tempo.com yaitu kasus siswi SMP $X$ di Jawa Barat diduga meninggal akibat bunuh diri karena takut gagal ujian nasional dan takut tidak dapat melanjutkan sekolah di tingkat berikutnya (Tirta, 2013). Hal serupa terjadi di kota Bali (tahun 2014), seorang siswa SMP bunuh diri dengan dasi sekolahnya karena takut gagal ujian nasional (tribunnews.com).

Kaitannya dengan rasa takut ini, sebenarnya rasa ini biasa dirasakan oleh semua individu. Rasa takut adalah salah satu emosi dasar yang dialami, diekspresikan, dan dipahami manusia semenjak kecil (Ekman, Sorenson, \& Friesen, dalam Michalcakova et al, 2013). Emosi takut didefinisikan sebagai perasaan tidak menyenangkan yang muncul sebagai respon normal pada bahaya yang nyata ataupun imajinasi. Emosi ini dianggap penting dan merupakan aspek adaptif dari perkembangan (Gullone, 2000). Rasa takut pada anak-anak berubah selama proses perkembangannya dan berkaitan dengan kognitif, persepsi, emosi dan perkembangan sosial (Owen, 1998).

Rasa takut yang awalnya menjadi emosi yang adaptif dan biasa, menjadi hal yang luar biasa apabila individu tidak mampu mengelolanya. Pemeliharaan perasaan takut ini membuat individu cenderung memelihara emosi negatif (Rice et al, 2009). Emosi negatif adalah emosi yang timbul pada diri individu diantaranya karena individu tidak dapat mencapai tujuannya atau keadaan yang mereka inginkan, atau jika tujuannya terancam atau akan terancam, atau adanya konflik diantara dua tujuan (Lazarus, 1991). Remaja lebih sering mengalami emosi yang negatif setiap harinya (Gullotta, 2005). Jika dibandingkan dengan orang dewasa, para remaja sangat cepat berubah intensitas emosi negatifnya. Emosi remaja berubah dalam merasakan emosi negatif dari intensitas lemah ke intensitas kuat dengan sangat cepat. Individu menjadi fokus tentang konsekuensi yang tidak diharapkan dari kegagalan yang dapat mengecewakan diri dan orang lain ( Elliot \& Thrash, 2004).

Perasaan takut gagal yang tinggi berdampak pada kemunculan emosi negatif yang berpengaruh pada psikologis dan fisik (misalnya: kecemasan, gangguan makan, malu, dan depresi) pada individu yang sering terlibat dalam tugas-tugas pencapaian prestasi (Conroy, 2001). Perasaan takut gagal menjadi hal yang mendasari kinerja yang menghindari tujuan, menimbulkan kecemasan, melemahkan kinerja, dan menyebabkan individu kehilangan minat dan akhirnya putus asa (Elliot \& McGregor, 2001; Conroy, Kaye, \& Fifer, 2007). Hal tersebut menunjukkan bahwa perasaan takut gagal memiliki implikasi penting dalam akademik siswa remaja awal dalam mencapai prestasinya.

Oleh karena itu, penting bagi siswa remaja untuk mampu mengelola emosinya, khususnya rasa takut yang secara natural muncul dalam benak mereka. Kemampuan memahami, merenungkan, dan mengatur emosi merupakan tugas penting pada masa anak-anak dan remaja (Saarni, 1997). Terlebih remaja sering merasakan emosi dengan intensitas tinggi (Engels et al, 2012), demikian halnya dengan perasaan takut gagal. Individu yang mampu mengelola emosinya dengan baik maka akan mengurangi intensitas emosinya atau mengubah emosi tersebut sehingga lebih efektif dalam mencapai tujuan (Gross \& Thompson, 2007).

Sagar, Lavellee, dan Spray (2009) mengungkapkan bahwa kemampuan meregulasi emosi dapat memengaruhi perasaan takut akan kegagalan. Regulasi 
emosi (Thompson, 1994) adalah suatu proses ekstrinsik dan intrinsik yang bertanggung jawab untuk memantau, mengevaluasi, dan memodifikasi reaksi emosional terutama yang secara intensif memengaruhi pencapaian tujuan seseorang. Individu yang sering merasakan emosi negatif cenderung menggunakan regulasi emosi yang maladaptif (Wante et al., 2016; Hughes, Gullone, Dudley, Tonge, 2010; Rusk, Tamir, Rothbaun, 2011; Herts, McLaughlin, Hazenbuhler, 2012). Kondisi emosi yang labil pada remaja menunjukkan bahwa remaja akan cenderung menggunakan regulasi emosi maladaptif dalam menghadapi situasi emosional.

Sementara Barret, Gross, Christensen, dan Benvenuto (dalam Manz, 2007) menyatakan bahwa emosi negatif yang diregulasi secara adaptif dapat meningkatkan kemampuan dalam menghadapi perubahan hidup atau penyesuaian diri (Gyurak, Gross, Etkin, 2011), membayangkan masa depan yang positif, mempercepat pengambilan keputusan, dan membantu mengatasi masalah (Tugade \& Fedrickson, 2007). Selain itu, bagi remaja sendiri, kemampuan mereka dalam meregulasi emosi dapat mengurangi resiko gangguan psikopatologis (Morris et al., 2003).

Meningkatkan pengetahuan tentang regulasi emosi pada masa remaja awal merupakan waktu yang tepat dalam memahami cara-cara adaptif yang dapat dilakukan dalam meregulasi emosi. Hal tersebut didukung oleh beberapa pendapat para ahli, antara lain pendapat McEwen dan Flouri (2009) yang menyatakan perlu melakukan program intervensi preventif dalam menangani masalah regulasi pada remaja. Morris, et al. (2003) juga menjelaskan terdapat beberapa alasan pentingnya mengeskplorasi cara meregulasi emosi pada masa remaja awal yaitu pada masa tersebut merupakan masa transisi sehingga banyak pengalaman emosional yang baru, terdapat faktor biologis seperti hormon yang turut memengaruhi regulasi emosi, dan gangguan psikopatologi yang meningkat selama fase remaja.

Hal tersebut di atas menunjukkan bahwa penting untuk dilakukan suatu usaha pencegahan dalam mengatasi emosi yang mengganggu pada masa remaja awal. Dalam penelitian ini, emosi yang disoroti berkaitan dengan emosi takut gagal karena emosi ini seringkali muncul pada situasi pencapaian prestasi dan berdampak buruk pada individu yang tidak dapat mengelolanya dengan tepat. Pencegahan yang dilakukan dalam penelitian ini merupakan pencegahan primer yang berkaitan dengan kesehatan psikososial. Pencegahan ini diarahkan kepada terwujudnya kehidupan jiwa yang berfungsi dan berkembang secara optimal serta aktif menyesuaikan diri dengan lingkungannya (Wiramihardja, 2005).

Penambahan pengetahuan adalah tahap awal dalam taraf kompetensi kognitif yaitu dalam mengenali, mendeskripsikan, menamakan, mendefinisikan dan memilih (Bloom dalam Azwar, 2016). Melalui bekal pegetahuan tersebut diharapkan siswa remaja awal dapat mengaplikasikan dalam kehidupan sehari-hari sehingga dapat terampil dalam meregulasi emosi secara adaptif.

Linnehan (1993) menyatakan pelatihan regulasi emosi merupakan pelatihan yang bertujuan mengenali emosi, mengurangi penderitaan emosi dan mengurangi kerentanan yang ditimbulkan emosi. Linnehan menekankan pada pentingnya individu mengenali emosinya dan menerima diri serta lingkungannya secara bersamaan. Prosedur penerimaan termasuk mindfullness (misalnya fokus pada saat sekarang, berdasarkan asumsi tidak menghakimi, dan fokus pada 
efektivitas). Selanjutnya, setelah individu mampu menerima dirinya maka perlu melakukan perubahan. Strategi perubahan menurut Linnehan (1993) dilakukan dengan cara menganalisis perilaku maladaptif, penguatan perilaku dengan reward, modifikasi kognitif, dan mengetahui strategi dasar yang dapat dilakukan (Rathus \& Miller, 2015). Gallo, McCulloch, Keil, Rockstroh (2009) juga menyatakan dengan mengubah cara berpikir terhadap situasi emosional dapat mengurangi pengalaman atau ekspresi negatif serta meningkatkan pengalaman atau ekspresi positif.

Penelitian ini melakukan modifikasi modul pelatihan regulasi emosi yang telah disusun oleh Rathus dan Miller (2015). Hal ini karena modul tersebut terbukti dapat membantu remaja dalam meregulasi emosi berlebih ketika dihadapkan pada sebuah permasalahan emosional (Rathus \& Miller, 2015). Dalam proses modifikasi, peneliti melakukan proses validasi modul dengan harapan dapat menghasilkan modul yang baik. Russel dan Johanningsmeier (1981) menyatakan modul yang baik merupakan modul yang bisa diterapkan dalam berbagai situasi, baik secara individu atau kelompok, lingkungan akademik atau non akademik, serta membawa perubahan positif bagi subjek.

Pada modul penelitian ini peneliti menggunakan pengujian validitas isi melalui professional judgement dan pengujian validitas empirik melalui uji lapangan dan penggunaan kelompok kontrol sebagai pembanding hasil perlakuan. Professional judgement adalah upaya validasi dengan meminta penilaian dari beberapa ahli. Penilaian tersebut akan digunakan sebagai masukan dan perbaikan untuk modul yang akan divalidasi secara empirik melalui uji coba lapangan. Sedangkan pengujian empirik dilakukan dengan cara mencobakan produk yang telah dikembangkan pada situsi nyata (Sugiyono, 2015)

Sedangkan pada pelaksanaannya, peneliti menggunakan metode observational learning. Proses pembelajaran ini merupakan hasil interaksi antara faktor perilaku, faktor lingkungan, dan faktor personal (Bandura, 1986). Perilaku merupakan hasil dari interaksi faktorfaktor tersebut, bukan hanya dorongan dari internal atau eksternal individu. Pembelajaran observasional merupakan proses pembelajaran melalui pengamatan terhadap pengalaman orang lain yang dijadikan model. Selanjutnya, individu menampilkan perilaku orang tersebut secara kognisi dan mengadopsinya (Santrock, 2002).

Menimbang dari teori yang telah dipaparkan, di mana Linehan (1993) menjelaskan tujuan dari pelatihan regulasi emosi adalah memudahkan untuk mengenali emosi, mengurangi penderitaan emosi dan mengurangi kerentanan yang ditimbulkan oleh emosi, maka peneliti membentuk suatu hipotesis bahwa modul "Gen Positif" valid dan dapat meningkatkan pengetahuan regulasi emosi takut gagal. Dengan hipotesis tersebut, penelitian ini bertujuan memvalidasi modul dan mengetahui sejauh mana peningkatan pengetahuan regulasi emosi takut gagal siswa remaja awal. Harapan peneliti agar penelitian ini memberikan manfaat teoritis berupa penambahan wawasan mengenai cara meningkatkan pengetahuan dan kemampuan regulasi emosi takut gagal siswa remaja awal, serta manfaat praktis sebagai masukan kepada tenaga pendidik dan psikolog pendidikan mengenai cara meningkatkan pengetahuan dan kemampuan regulasi emosi takut gagal pada siswa remaja awal. 


\section{Metode}

Partisipan penelitian

Partisipan penelitian adalah 12 siswa remaja awal. Karakteristik partisipan penelitian adalah siswa/i yang berusia 1315 tahun dengan perolehan skor pengetahuan regulasi emosi takut gagal pada kategori rendah ke sedang, belum pernah mengikuti pelatihan sejenis, dan bersedia berpartisipasi dalam penelitian.

\section{Instrumen penelitian}

Instrumen pertama yang digunakan dalam penelitian ini adalah modul pelatihan regulasi emosi. Modul ini dimodifikasi dari modul pelatihan regulasi emosi oleh Rathus dan Miller (2015). Isi modul terdiri atas keterampilan regulasi emosi yaitu usaha dalam memahami emosi, mengurangi kerentanan emosi, mengubah emosi yang tidak diinginkan dan mengurangi penderitaan emosi. Intstrumen kedua adalah lembar tes pengetahuan regulasi emosi berisi tentang pengetahuan mengenai mengenali, mengurangi kerentanan, mengurangi penderitaan dan mengubah respon emosi takut gagal. Tes pengetahuan ini dikembangkan berdasarkan teori Linnehan (1993) yaitu mengenali emosi, mengurangi kerentanan, mengurangi penderitaan dan mengubah respon emosi takut gagal. Materi mengenai mengenali emosi lebih dikhususkan pada emosi takut gagal yang disusun berdasarkan teori Conroy (2003). Tes pengetahuan ini terdiri atas 15 aitem dengan menggunakan pilihan jawaban benar (skor 1) dan salah (0). Blueprint tes pengetahuan regulasi emosi takut gagal dapat dilihat pada tabel 3. Instrumen ketiga menggunakan lembar observasi proses pelatihan. Instrumen ini diisi oleh observer dalam menilai preforma trainer, keaktifan peserta dan proses pelatihan sebagai data penunjang untuk melihat keberhasilan pelatihan.

\section{Rancangan penelitian}

Rancangan penelitian yang akan digunakan yaitu untreated control group designs with dependent pretets and posttest samples. Rancangan penelitian ini menggunakan kelompok eksperimen dan kelompok kontrol dimana masing-masing kelompok akan diberikan pretest dan postest (Shadish, Cook, \& Campbell, 2002). Rancangan penelitian sebagai berikut :

Kelompok eksperimen : $\mathrm{NR}_{1} \mathrm{XO}_{2}$

Kelompok kontrol $\quad: \mathrm{NRO}_{1} \quad \mathrm{O}_{2}$

\section{Keterangan : \\ NR : Non Random \\ $\mathrm{O}_{1}$ : Pretest (skor tes pengetahuan regulasi emosi takut gagal) \\ $\mathrm{O}_{2}$ : Posttest (skor tes pengetahuan regulasi emosi takut gagal) \\ $X$ : Perlakuan yaitu pelatihan regulasi emosi}

\section{Prosedur penelitian}

Tahapan Persiapan, meliputi kegiatan penyusunan instrumen untuk mengukur pengetahuan regulasi emosi takut gagal serta uji validitas dan reliabilitas tes pengetahuan regulasi emosi takut gagal. Pengujian validitas alat ukur ini menggunakan validitas isi. Uji validitas ini meminta penilaian dari 10 orang penilai (expert) yang kompeten mengenai alat ukur tersebut. Penilaian dilakukan oleh tiga dosen yang memiliki pengetahuan mengenai regulasi emosi takut gagal, satu dosen yang pernah meneliti dan membuat alat ukur pengetahuan regulasi emosi, empat praktisi yang memiliki pengalaman dalam membuat dan memvalidasi alat ukur psikologi khususnya tes kognitif, dua 
akademisi yang memiliki pengetahuan mengenai alat ukur psikologi dan psikologi kognitif. Hasil penilaian dari panel expert dianalisis dengan mengg-unakan formula CVR menunjukkan angka berkisar antara 0,4 hingga 0,8. Angka CVR bergerak antara $-1,00$ sampai dengan $+1,00$. Bilamana CVR $>$ 0,00 berarti bahwa $50 \%$ lebih dari SME dalam panel menyatakan aitem adalah esensial. Semakin lebih besar CVR dari angka 0 maka semakin esensial dan semakin tinggi validitas isinya (Azwar, 2016). Berdasarkan hasil perhitungan CVR maka dapat disimpulkan bahwa aitem pengetahuan emosi takut gagal memiliki validitas isi yang baik.

Uji reliabilitas dilakukan pada siswa remaja awal sebanyak 84 siswa yang memiliki karakteristik yang sama dengan subjek penelitian. Pengukuran reliabilitas tes pengetahuan dalam penelitian ini menggunakan koefisien cronbach alpha dan melihat indeks daya beda aitem. Berdasarkan hasil uji coba tes pengetahuan diperoleh hasil koefisien alpha sebesar 0,827 dan indeks daya beda aitem (korelasi pointbiserial) yang bergerak dari 0,43 - 0,62. Berdasarkan uji korelasi ini maka aitem yang layak digunakan terdiri atas 15 aitem dari 38 aitem yang telah direncanakan.

Proses validasi isi modul dilakukan dengan menggunakan professional judgement modul, dan evaluasi modul. Validasi modul dilakukan oleh panel expert dengan memberikan analisis rasional dan penilaian secara kuantitatif dan kualitatif. Validitas isi dilakukan oleh panel ahli yaitu terdiri dari enam orang. Penilaian dilakukan oleh dua orang dosen psikologi yang memiliki pengalaman dalam pembuatan modul regulasi emosi, tiga orang dosen yang memiliki pengalaman dalam pembuatan modul dan melakukan pelatihan kepada remaja awal, satu praktisi yang berpengalaman dalam melakukan pelatihan pada remaja. Evaluasi modul dilakukan berdasarkan hasil penilaian para ahli. Revisi modul akan dilakukan jika diperlukan untuk meningkatkan kualitas modul.

Validasi Empirik melalui proses uji coba di lapangan dilakukan melalui kegiatan pre-test menggunakan tes pengetahuan regulasi emosi takut gagal, pengarahan singkat (briefing) antara fasilitator dan observer, pengarahan kepada observer dan pelaksanaan pelatihan regulasi emosi takut gagal. Pretest diberikan kepada siswa SMP kelas VIII di SMP $X$ menggunakan tes pengetahuan regulasi emosi takut gagal. Siswa yang mendapatkan kategori skor pengetahuan regulasi emosi takut gagal rendah ke sedang dipilih menjadi subjek penelitian. Seblum proses intervensi dilaksanakan peneliti memberikan pengarahan singkat kepada fasilitator berkaitan dengan materi dan proses intervensi yang akan dilaksanakan. Fasilitator dalam penelitian ini adalah psikolog yang telah memiliki pengalaman dalam memberikan pelatihan kepada siswa remaja. Proses ini dilakukan agar fasilitator dapat memahami secara utuh berkaitan dengan isi modul dan teknik penyampaian. Proses diskusi dengan fasilitator juga membicarakan mengenai kesesuaian waktu pelatihan yang disediakan dengan aplikasi nantinya pada saat pelatihan.

Observer juga mendapatkan pengarahan sebelum proses intervensi. Mahasiswa magister profesi yang menjadi observe dalam penelitian ini. Observer diberikan pengarahan berkaitan dengan beberapa aspek yang perlu diobservasi dan dinilai, seperti yang berkaitan dengan cara penyampaian materi oleh fasilitator, dinamika pada setiap sesi, dan respon peserta selama mengikuti proses pelatihan. Pelatihan dilaksanakan berdasarkan modul yang telah melalui proses penilaian dan juga perbaikan. Partisipan penelitian 
merupakan siswa remaja awal yang telah melalui proses pre-test sebelum pelaksanaan penelitian, menunjukkan skor yang berada pada kategori rendah ke sedang pada tes pengetahuan regulasi emosi, dan bersedia mengikuti serangkaian kegiatan pelatihan. Post-test dilakukan setelah seluruh proses pelatihan berakhir pada hari pelaksanaan pelatihan guna melihat adanya perubahan skor pengetahuan regulasi emosi takut gagal.

Data dalam penelitian ini dianalisis menggunakan statistik Mann Whitney $U$ Test. Tujuan dari analisis tersebut adalah untuk mengetahui perbedaan perubahan skor pretest-postest perasaan takut gagal antara kelompok eksperimen dan kelompok kontrol.

\section{Hasil}

Peneliti mengembangkan modul berdasarkan teori regulasi emosi yang dikembangkan oleh Linnehan (1993) pada Rathus \& Miller (2015). Penelitian ini melibatkan enam ahli untuk memberikan penilaian terhadap kesesuaian isi modul dengan tujuan pembuatan modul yaitu modul regulasi emosi takut gagal dapat meningkatkan skor pengetahuan regulasi emosi takut gagal siswa remaja awal. Penilai terdiri atas psikolog yang menguasai materi regulasi emosi, psikolog yang berpengalaman di bidang pelatihan dan dosen yang memahami dinamika pelatihan untuk remaja.

Hasil penilaian tersebut selanjutnya diolah menggunakan analisis aiken's $\mathrm{V}$ dengan hasil tampak pada Tabel 1.

Menurut Azwar (2012) skor aiken's V minimal 0,5 sudah dapat diterima dan dianggap memuaskan. Berdasarkan tabel 1, setiap sesi dari modul "Gen Positif" memiliki skor yang bergerak dari 0,875 hingga 0,916 Angka tersebut menunjukkan bahwa modul memiliki validitas isi yang baik.

Guna peningkatan kualitas modul, selain meminta penilaian secara kuantitatif kepada ahli, peneliti juga meminta penilaian secara kualitatif terkait modul. Selanjutnya saran yang diberikan oleh ahli yang digunakan untuk memperbaiki modul. Berikut ini beberapa rekomendasi perbaikan yang diberikan oleh para penilai yaitu perlu mempertimbangkan alokasi waktu yang disesuaikan dengan jumlah peserta, menggunakan ilustrasi presentasi yang menarik dan sederhana ketika menyampaikan konsep psikologi, mengingat peserta adalah remaja yang tidak memiliki latar belakang psikologi, serta memberikan ice breaking sederhana untuk setiap perpindahan sesi khususnya selepas istirahat.

Uji validasi empirik melalui penelitian eksperimen untuk mengetahui pengaruh modul terhadap pengetahuan regulasi emosi takut gagal siswa remaja awal. Setelah mengetahui validitas isi dari modul, selanjutnya peneliti melakukkan

Tabel 1.

Hasil penghitungan validasi isi modul setiap sesi menggunakan analisis aiken's V

\begin{tabular}{lccccccc}
\hline Sesi pelatihan & \multicolumn{4}{c}{ Penilai } & & Aikens's \\
& A & B & C & D & E & F & V \\
\hline Sesi 1 & 5 & 5 & 4 & 4 & 5 & 4 & 0,875 \\
Sesi 2 & 5 & 5 & 4 & 4 & 5 & 5 & 0,916 \\
Sesi 3 & 5 & 5 & 4 & 4 & 5 & 5 & 0,916 \\
Sesi 4 & 5 & 5 & 4 & 4 & 5 & 5 & 0,916 \\
\hline
\end{tabular}


penelitian eksperimen untuk mengetahui pengaruh modul dalam meningkatkan pengetahuan regulasi emosi takut gagal siswa remaja awal. Penelitian ini melibatkan tujuh subjek pada kelompok eksperimen (KE) dan lima subyek pada kelompok kontrol (KK).

Hasil eksperimen dianalisis secara kuantitatif melalui uji prasyarat dan juga uji hipotesis. Tujuan dilakukan uji normalitas adalah untuk mengetahui distribusi data apakah menyebar secara normal atau tidak. Uji normalitas dilakukan dengan metode liliefors dan shaphiro wilk dengan menggunakan perangkat SPSS. Hasil uji normalitas skor pengetahuan regulasi emosi takut gagal dapat dilihat pada Tabel 2.

Berdasarkan Tabel 2 diketahui bahwa pada saat pretest dan postest nilai signifikansi pada kelompok eksperimen memiliki nilai $\mathrm{p}=0,012(\mathrm{p}<0,05)$ sedangkan kelompok kontrol nilai $p=0,314(p>0,05)$ yang berarti data pada kelompok eksperimen tidak terdistribusi normal sedangkan data pada kelompok kontrol terdistribusi normal.

Uji homegenitas dilakukan untuk mengetahui apakah varian data antara kedua kelompok memiliki sifat yang homogen atau tidak. Uji homogenitas dilakukan dengan metode levene's test pada uji Mann Whitney dengan menggunakan SPSS. Varian data dikatakan homogen ketika nilai signifikansi $p>0,05$. Penelitian ini meiliki nilai homogenitas 0,840 yang berarti data tersebut homogen. Hasil uji homogenitas pengetehuan regulasi emosi takut gagal dapat dilihat pada Tabel 3.

Uji hipotesis pada eksperimen ini dianalisis dengan menggunakan Mann Whitney $U$ Test yang bertujuan menguji perbedaan skor pretest dan postest serta menganalisis gain score antar kelompok eksperimen dan kontrol (between subject). Hasil perhitungan statistik diperoleh data sebagai berikut:

Tabel 2.

hasil uji normalitas data pengetahuan regulasi emosi takut gagal

\begin{tabular}{llccccccc}
\hline & \multirow{2}{*}{$\begin{array}{l}\text { kelompok } \\
\text { penelitian }\end{array}$} & \multicolumn{4}{c}{ Kolmogorov-Smirnov(a) } & \multicolumn{2}{c}{ Shapiro-Wilk } \\
& & Statistic & df & Sig. & Statistic & df & Sig. \\
\hline $\begin{array}{l}\text { gain } \\
\text { score }\end{array}$ & $\begin{array}{l}\text { kelompok } \\
\text { eksperimen } \\
\text { kelompok }\end{array}$ &, 338 & 7 &, 015 &, 769 & 7 &, 020 \\
& kontrol & 231 & 5 &, $200\left(^{*}\right)$ &, 881 & 5 &, 314 \\
\hline
\end{tabular}

Tabel 3.

Uji homogenitas

\begin{tabular}{llrrrr}
\hline & & $\begin{array}{c}\text { Levene } \\
\text { Statistic }\end{array}$ & \multicolumn{1}{c}{ df1 } & \multicolumn{1}{c}{ df2 } & Sig. \\
\hline gain score & Based on Mean &, 003 & 1 & 10 &, 955 \\
& $\begin{array}{l}\text { Based on Median } \\
\text { Based on Median and }\end{array}$ &, 005 & 1 & 10 &, 946 \\
$\begin{array}{l}\text { with adjusted df } \\
\text { Based on trimmed } \\
\text { mean }\end{array}$ &, 005 & 1 & 9,081 &, 946 \\
& & & 1 & 10 &, 994 \\
\hline
\end{tabular}


Tabel 4.

Uji hipotesis Mann Whitney U Test (N=12)

\begin{tabular}{lr}
\hline & gain score \\
\hline Mann-Whitney U & 5,000 \\
Wilcoxon W & 20,000 \\
$Z$ & $-2,121$ \\
& \\
Asymp. Sig. (2-tailed) &, 034 \\
Exact Sig. [2*(1-tailed Sig.)] &, $048(\mathrm{a})$ \\
\hline
\end{tabular}

Berdasarkan tabel 4 dapat diketahui bahwa skor $Z$ sebesar-2,121 dengan nilai sig atau $\mathrm{P}$ value sebesar $0,034(\mathrm{p}<0.05)$ yang berarti terdapat perbedaan yang signifikan rerata antara kelompok eksperimen dan kelompok kontrol setelah diberi perlakuan. Hasil tersebut menunjukkan bahwa modul "Gen Positif" dapat meningkatkan pengetahuan regulasi emosi takut gagal siswa remaja awal pada kelompok pada kelompok kontrol tidak terdapat perubahan yang signifikan sebelum dan sesudah diberi perlakuan.

Selanjutnya, dilakukan analisis untuk mengetahui perbedaan pengetahuan regulasi emosi takut gagal pada masingmasing kelompok sebelum dan sesudah diberikan perlakuan dengan menggunakan Wilcoxon Signes Rank Test. Skor rerata pengetahuan regulasi emosi takut gagal sebelum diberi perlakuan (pre-test) sebesar 6,14, sedangkan rerata setelah diberi perlakuan (post-test) sebesar 8,57 dengan $\mathrm{z}=$ $-2,414$ dengan $\mathrm{p}=0,016(\mathrm{p}<0,05)$, yang berarti terdapat perbedaan rerata pada kelompok eksperimen sebelum dan sesudah diberi perlakuan. Hasil tersebut menunjukkan bahwa terdapat perbedaan yang signifikan pengetahuan regulasi emosi takut gagal sebelum dan sesudah perlakuan diberikan pada kelompok

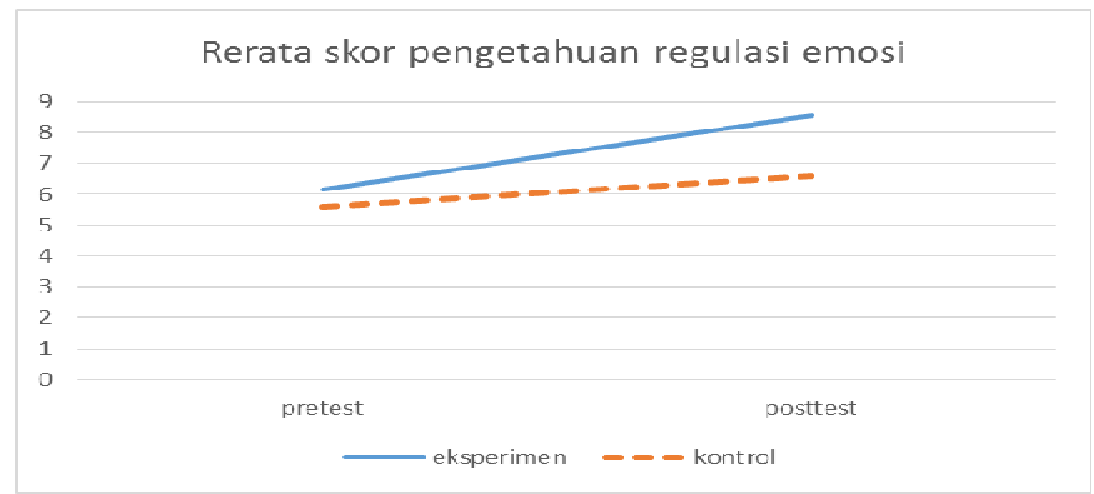

Gambar 1. Rerata skor pengetahuan regulasi emosi takut gagal

eksperimen dibandingkan dengan kelompok kontrol yang tidak menerima perlakuan. Gambar di bawah ini menunjukkan perubahan rerata skor pengetahuan regulasi emosi takut gagal pada kelompok eksperimen dan kelompok kontrol.

Berdasarkan gambar 1 diketahui bahwa terdapat perubahan rerata pengetahuan regulasi emosi pada kelompok eksperimen sebelum perlakuan dan setelah diberi perlakuan. Sedangkan eksperimen.

Sedangkan rerata pada kelompok kontrol menunjukkan rerata pretest adalah 5,6 dan post-test adalah 6,6 dengan $\mathrm{Z}=$ 1,890 dan $p=0,059 \quad(p>0,05)$, yang berarti bahwa tidak terdapat perbedaan yang signifikan antara pengetahuan regulasi emosi takut gagal sebelum dan sesudah diberi perlakuan. Hasil analisis tersebut menunjukkan bahwa perlakuan berupa modul "Gen Positif" yang diberikan kepada kelompok eksperimen terbukti 
dapat meningkatkan pengetahuan regulasi emosi takut gagal siswa remaja awal.

Uji empirik modul dilaksanakan dengan jumlah peserta 7 siswa remaja awal yang bersekolah di SMP Piri Ngaglik Sleman Yogyakarta. Evaluasi pelaksanan program modul "Gen Positif" dilakukan oleh empat observer yang selanjutnya dianalisis dengan menggunakan aiken's $V$. Penilaian yang diberikan tampak pada Tabel 5.

\section{Diskusi}

Hasil penelitian yang dilakukan menunjukkan bahwa modul pelatihan "Gen Positif" valid untuk meningkatkan pengetahuan dan kemampuan regulasi emosi takut gagal siswa remaja awal. Tujuan penelitian ini adalah untuk memvalidasi modul dan mengetahui peningkatan skor pengetahuan regulasi emosi takut gagal siswa remaja awal pasca-

Tabel 5.

Evaluasi pelaksanaan program modul "Gen Positif"

\begin{tabular}{|c|c|c|c|c|c|c|c|}
\hline \multirow{2}{*}{ Aspek } & \multirow{2}{*}{ Indikator } & \multicolumn{5}{|c|}{ Observer } & \multirow{2}{*}{$\begin{array}{r}\text { Koefisien } \\
\text { validitas }\end{array}$} \\
\hline & & 1 & 2 & 3 & 4 & 5 & \\
\hline \multirow{4}{*}{$\begin{array}{l}\text { Fasilitas } \\
\text { pelatihan }\end{array}$} & peralatan/perlengkapan/media yang digunakan & 5 & 5 & 4 & 3 & 4 & 0,8 \\
\hline & fasilitas pelatihan (ruangan, kursi, konsumsi) & 3 & 4 & 4 & 3 & 4 & 0,65 \\
\hline & an, dll) & & & & & & \\
\hline & layanan pelatihan (tepat waktu, keramah & 4 & 3 & 3 & 4 & 4 & 0,65 \\
\hline \multirow{3}{*}{$\begin{array}{l}\text { Kualitas } \\
\text { fasilitator }\end{array}$} & Sistematika penyajian materi & 5 & 4 & 4 & 4 & 4 & 0,8 \\
\hline & Penguasaan materi & 5 & 5 & 5 & 3 & 4 & 0,85 \\
\hline & Kemampuan memastikan pemahaman materi & 5 & 3 & 4 & 4 & 5 & 0,8 \\
\hline \multirow{5}{*}{$\begin{array}{l}\text { Proses } \\
\text { pelatihan }\end{array}$} & Metode penyajian materi & 4 & 4 & 4 & 4 & 4 & 0,8 \\
\hline & Bentuk penyajian materi & 4 & 4 & 4 & 4 & 4 & 0,8 \\
\hline & $\begin{array}{l}\text { Kesinambungan antara masing-masing materi } \\
\text { dalam sesi }\end{array}$ & 4 & 5 & 3 & 4 & 4 & 0,75 \\
\hline & Ketepatan waktu pelaksanaan dengan jadwal & 3 & 3 & 3 & 3 & 3 & 0,5 \\
\hline & Beban muatan materi & 4 & 3 & 4 & 3 & 4 & 0,65 \\
\hline \multirow{4}{*}{$\begin{array}{l}\text { Kondisi } \\
\text { Peserta }\end{array}$} & Partisipasi peserta & 4 & 5 & 4 & 4 & 4 & 0,8 \\
\hline & Keaktifan peserta & 4 & 4 & 4 & 3 & 4 & 0,7 \\
\hline & Kerjasama antar peserta & 4 & 4 & 3 & 3 & 4 & 0,65 \\
\hline & Perhatian terhadap materi yang diberikan & 4 & 5 & 4 & 4 & 4 & 0,8 \\
\hline
\end{tabular}

Berdasarkan evaluasi dari observer, pelaksanaan program modul "Gen Positif berjalan sesuai dengan yang direncanakan. Modul "Gen Positif memiliki koefisien yang tinggi pada aspek kualitas fasilitator. Pada aspek teknis pelaksanaan terdapat beberapa catatan yaitu alokasi waktu yang kurang sesuai disebabkan keterlambatan peserta dan pembahasan yang terlalu lama pada sesi pengenalan emosi. Hal tersebut memengaruhi alokasi waktu yang diberikan pada sesi yang lain. pemberian pelatihan pada kelompok eksperimen. Selanjutnya akan dijelaskan mengenai langkah-langkah mengembangkan suatu modul sebelum memaparkan mengenai peningkatan skor pengetahuan regulasi emosi takut gagal.

Peneliti menuyusun modul pelatihan "Gen Positif" dengan memodifikasi modul Rathus \& Miller (2015). Setelah peneliti selesai menyusun modul, selanjutnya dilakukan proses penilaian dari beberapa ahli untuk mengetahui kesesuaian antara modul yang disusun dengan landasan teori 
yang digunakan. Hasil penilaian dari panel ahli dengan menggunakan formula aiken's $V$ diperoleh hasil berkisar antara 0,8750,916 hal ini menunjukkan bahwa koefisien validitas isi modul pelatihan "Gen Positif" dianggap baik. Menurut Azwar (2012) nilai koefisien validitas di atas 0,5 dianggap memuaskan sehingga dapat disimpulkan bahwa modul "Gen Positif" memiliki validitas isi yang baik. Peneliti juga melakukan beberapa perbaikan sebelum melakukan uji empirik di lapangan guna meningkatkan kualitas modul berdasarkan saran dari panel expert.

Langkah-langkah yang dilakukan peneliti dalam menyusun modul yang valid berdasarkan teori Russel \& Johanningsmeier (1981). Langkah pertama yaitu menentukan tujuan modul secara spesifik. Tujuan modul "Gen Positif" adalah untuk meningkatkan pengetahuan regulasi emosi takut gagal siswa remaja awal sehingga dapat menjadi usaha pencegahan melakukan regulasi emosi maladaptif yang tidak efektif dalam proses pemecahan masalah. Langkah kedua yaitu penyusunan tes kompetensi yang valid. Langkah ini dilakukan untuk mengetahui sejauh mana subjek dapat mencapai tujuan modul (Russel \& Johanningsmeier, 1981). Penelitian ini menggunakan tes pengetahuan regulasi emosi takut gagal yang melalui proses penilaian dari beberapa expert. Hasil penilaian dari panel expert diformulasikan dengan teknik CVI dengan perolehan hasil sekitar 0,874 dan koefisien reliabilitasnya dengan nilai $\mathrm{r}=$ 0,852

Langkah ketiga yaitu penentuan karakteristik subjek disesuaikan dengan materi yang akan diberikan. Karakteristik tersebut yang sifatnya tidak berubah dalam waktu singkat seperti usia, kelas, inteligensi dan status ekonomi. Karakteristik subjek dari penelitian ini adalah siswa remaja awal sehingga modul yang dimodifikasi merupakan modul regulasi emosi yang diperuntukkan bagi remaja Rathus \& Miller (2015). Materi yang terdapat pada modul disesuaikan dengan kemampaun remaja dalam memahami pengetahuan baru. Selanjutnya, langkah keempat yaitu metode pembelajaran yang mendukung hasil yang optimal. Penelitiaan ini menggunakan metode pembelajaran observasional dengan cara ceramah, menonton video, melakukan permainan sederhana, mengisi lembar kerja, dan diskusi untuk membantu subjek memahami materi yang diberikan.

Langkah kelima dilakukan dengan percobaan pada subjek melalui uji empirik untuk melihat sejauh mana modul dapat memberikan perubahan positif terhadap subjek. peneliti melakukan penelitian eksperimen kepada subjek yang telah ditentukan untuk melihat efek dari modul yang telah disusun.

Hasil uji empirik terhadap 12 subjek yang terdiri dari tujuh orang siswa remaja awal dalam kelompok eksperimen dan lima orang siswa remaja awal dalam kelompok kontrol, diperoleh perbedaan yang signifikan antara skor rerata pada kelompok eksperimen dan kelompok kontrol (between subject) setelah diberi perlakuan $\mathrm{Z}=-2,121$ dan $\mathrm{p}=0,034(\mathrm{p}<0,005)$. Selain itu terdapat perbedaan skor rerata dalam kelompok (within subject) yaitu perubahan skor rerata pada kelompok eksperimen dengan skor rerata pretest sebesar 6,142 sedangkan posttest sebesar 8,571 dengan $\mathrm{z}=-2,414$ dengan $\mathrm{p}=0,016$ $(\mathrm{p}<0,05)$, sedangkan pada kelompok kontrol tidak terdapat perubahan yang signifikan dengan skor rerata pretest sebesar 5,6 dan postest 6,6 dengan $Z=-1,890$ dengan $p=0,059 \quad(p>0,05)$. Berdasarkan hasil analisis tersebut maka dapat dikatakan bahwa hipotesis pada penelitian ini dapat diterima. 
Dengan demikian, modul "Gen Positif" dapat digunakan untuk meningkatkan pengetahuan regulasi emosi takut gagal. Melalui pengetahuan ini siswa remaja awal memiliki informasi yang dapat digunakan dalam menghadapi situasi yang menimbulkan emosi takut gagal. Bekal pengetahuan ini menjadikan remaja lebih menganali emosi secara menyeluruh dan mengenali emosi takut gagal secara khusus, mengetahui cara untuk menghimpun kekuatan dalam mengantisipasi kerentanan emosi takut gagal, mengetahui cara yang dapat dilakukan agar tidak merasakan tekanan emosional takut gagal yang berkepanjang, dan mengetahui cara mengubah respon emosi saat berhadapan dengan situasi emosional takut gagal. hasil penelitian ini didukung dengan penelitian sebelumnya yang mengatakan bahwa kemampuan regulasi emosi dapat memengaruhi emosi takut gagal (Sagar, Lavellee, dan Spray, 2009). Ketika pengetahuan ini diaplikasikan dalam kehidupan sehari-hari maka akan menjadikan individu menjadi mampu dan terampil dalam melakukan regulasi emosi.

Thompson (1994) menyatakan regulasi emosi merupakan proses ekstrinsik dan intrinsik yang bertanggungjawab memantau, mengevaluasi, dan modifikasi reaksi emosional yang intensif terutama yang memengaruhi pencapaian tujuan. Melalui pelatihan dengan modul "Gen Positif" ini membantu remaja dalam proses ekstrinsik berupa sosialisasi berkaitan dengan cara adaptif yang dapat dilakukan dalam menghadapi situasi emosional takut gagal sehingga lebih efektif dalam mencapai tujuan.

Pelatihan mengenai regulasi emosi sangat tepat diberikan pada siswa remaja awal karena banyaknya perubahan yang terjadi pada masa tersebut yang memungkinkan munculnya gangguan emosional, dengan demikian melalui peningkatan regulasi emosi sealama masa remaja ini akan membantu remaja memahami perubahan individu dalam kesehatan psikologis dan mengurangi resiko gangguan psikologis (Morris et al., 2003).

Pengetahuan yang diperoleh peserta dengan modul "Gen Positif" pada sesi pertama berkaitan dengan pengenalan emosi. Pada sesi ini peserta mendapatkan pamahaman baru tentang definisi emosi. Pada awalnya, peserta menganggap emosi lebih kepada marah atau sensitif dengan hal tertentu. Melalui pelatihan ini peserta memahami bahwa emosi terdiri atas emosi negatif dan positif serta manfaat yang diperoleh dari emosi tersebut. Peserta mengetahui bahwa memiliki kedua emosi tersebut adalah hal yang wajar sepanjang tidak kaku dan diregulasi dengan cara yang adaptif. Selain itu peserta mendapat pengetahuan baru tentang pentingnya mengetahui proses terbentuknya emosi serta mengenali emosi primer dan sekunder sehingga dapat memudahkan peserta dalam menerapkan strategi regulasi emosi.

Sesi kedua, peserta mendapatkan pengetahun tentang mengurangi kerentanan emosional dengan memperkuat hal positif dalam kehidupan individu. Peserta diperkenalkan dengan " $A B C$ PLEASE" sebagai teknik dalam mengurangi kerentanan. Pada sesi ini, peserta mulai sulit konsentrasi karena proses pelatihan yang cukup panjang dan sesi ini lebih banyak mendengarkan ceramah dan mengerjakan lembar kerja. Oleh karena itu, untuk mengembalikan konsentrasi peserta fasilitator dan cofasilitator menambahkan aktivitas tepuktepuk sederhana yang telah dikomunikasikan sebelumnya pada peneliti. Hal ini menjadi masukan dalam 
penyempurnaan modul saat diaplikasikan dilapangan.

Sesi ketiga, peserta mendapatkan pengetahuan tentang mengurangi penderitaan emosi dengan mindfullness (The Wave Skill). Pada sesi ini peserta diajak untuk menyelami emosi mereka dan menerimanya. Peserta diajak melakukan relaksasi pernapasan dan imajinasi dengan arahan dari fasilitator. Pada sesi ini, pada awalnya beberapa peserta tampak tidak mau mengikuti sesi ini namun selang beberapa waktu semua peserta dapat mengikuti aktiviatas tersebut dengan baik. Respon peserta setelah sesi ini berlangsung berbeda-beda ada yang tersenyum, ada yang biasa saja, dan ada yang menangis. Terdapat lima peserta merasakan rileks setelah kegiatan tersebut dan dua peserta menyatakan tidak merasakan apa-apa. Pada sesi ini, peneliti kurang memperhitungkan kejadian-kejadian yang luar biasa. Berdasarkan masukan dari observer perlu menambahkan catatan mengenai hal-hal yang perlu dilakukan ketika ada peserta yang merespon dengan hal-hal yang tidak biasa.

Sesi keempat, peserta mendaptkan pengetahuan tentang mengurangi respon emosi melalui pemecahan masalah dan opposite action. Sesi pemecahan masalah mengajak peserta untuk mengenali fakta dan menentukan langkah-langkah pemecahan masalah. Pada sesi ini peserta membutuhkan pendampingan secara lebih intensif karena beberapa peserta cukup sulit menyampaikan permsalahan yang mengganggu dan menentukan soluasi dari permasalahan tersebut. Pada sesi ini peserta semakin terbuka dalam mengkomunikasikan emosinya kepada orang lain. Proses pengaplikasian dilapangan berkaitan dengan sesi ini perlu diperlebar lagi alokasi waktunya sehingga peserta lebih merasakan manfaatnya.
Penelitian ini memiliki keterbatasan dalam pelaksanannya yaitu waktu penelitian yang relatif singkat. Hal ini dilakukan karena keterbatasan waktu yang dimiliki oleh peneliti. Selain itu, jumlah subjek penelitian yang terbatas juga menjadi kelemahan penelitian.

\section{Kesimpulan}

Berdasarkan hasil penelitian dapat disimpulkan bahwa Modul "Gen Positif" valid secara konten dan empirik untuk meningkatkan pengetahuan regulasi emosi takut gagal siswa remaja awal. Maka modul "Gen Positif" dapat digunakan untuk meningkatkan pengetahuan regulasi emosi takut gagal. Melalui pengetahuan dari pelatihan tersebut siswa remaja awal dapat dalam menghadapi situasi yang menimbulkan emosi takut gagal. Bekal pengetahuan ini menjadikan remaja lebih menganali emosi secara menyeluruh dan mengenali emosi takut gagal secara khusus, mengetahui cara untuk menghimpun kekuatan dalam mengantisipasi kerentanan emosi takut gagal, mengetahui cara yang dapat dilakukan agar tidak merasakan tekanan emosional takut gagal yang berkepanjang, dan mengetahui cara mengubah respon emosi saat berhadapan dengan situasi emosional takut gagal.

\section{Saran}

Terdapat beberapa hal yang dapat peneliti rekomendasikan berdasarkan hasil penelitian yaitu 1) modul "Gen Positif" dapat digunakan sebagai salah satu cara dalam meningkatkan pengetahuan regulasi emosi takut gagal siswa remaja awal; 2) peneliti berikutnya dapat mengembangkan modul "Gen Positif" yang bertujuan pada peningkatan keterampilan dan dampaknya pada emosi takut gagal yang dimiliki seseorang. 


\section{Kepustakaan}

Azwar, S. (2012). Metode penelitian.

Yogyakarta: Pustaka Pelajar.

Azwar, S. (2016). Konstruksi tes kemampuan kognitif. Yogyakarta: Pustaka Pelajar.

Bandura, A. (1986). Social foundations of thought and action: A Social cognitive theory. Englewood Cliffs, NJ: Prentice-Hall.

Belanger, J. J., Lafreniere, M. A. K., Vallerand, R. J., \& Kruglanski, A. W. (2013). Driven by fear: The effect of success and failure information on passionate individuals' performance. Journal of Personality and Social Psychology. 104(1), 180-195.

Birney, R. C., Burdick, H., \& Teevan, R. D. (1969). Fear of failure. New York: Van Nostrad.

Conroy, D. E., Poczwardowski, A., \& Henschen, K. P. (2001). Evaluative criteria and consequences associated with failure and success for elite athletes and performing artists. Journal of Applied Sport Psychology, 13, 300-322.

Conroy, D. E., Willow, J. P., \& Metzler, J. N. (2002). Multidimensional fear of failure measurement: The performance failure appraisal inventory. Journal of Applied Sport Psychology, 14, 76-90.

Conroy, D. E. (2003). Representational Models Associated With Fear of Failure in Adolescents and Young Adults. Journal of Personality, 71(50), 757-784. doi: 10.1111/1467-6494.710 5003.

Conroy, D. E., Kaye, M. P., \& Fifer, A. M. (2007). Cognitive links between fear of failure and perfectionism. Journal of Rational-Emotive \& Cognitive-Behavior Therapy, 25(4).
Diener, C. I., \& Dweck, C. S. (1978). An analysis of learned helplessness: Continuous changes in performance, strategy, and achievement cognitions following failure. Journal of Personality And Social Psychology, 36, 451-462. doi: 10.1037/0022-3514.36.5.451.

Eccles, J. S., Wigfield,A., \& Schiefele, U. (1998). Motivation to succeed. In W. Damon (Series Ed.) \& N. Eisenberg (Ed.), Handbook of child psychology: Vol. 3. Social, emotional, and personality development (5th ed., pp. 1017-1095). New York: Wiley.

Elliot, A. J., \& McGregor, H. (2001). A 232 achievement goal framework. Journal of Personality And Social Psychology, 80, 501-519.

Elliot, A. J., \& Thrash, T. M. (2004). The intergenerational transmission of fear of failure. Personality and Social Psychology Bulletin, 30, 957-971.

Engels, R. C. M. E., English, T., Evers, C., Geenen, R., Gross, J. J., Ha, T., Larsen, J. K., Middendorp, H. V., Vermulst, Ad.A. (2012). Emotion regulation in adolescence: A prospective study of expressive supression and deppressive symptoms. The Journal of Early Adolescence, 33(2), 184-200

McEwen C, Flouri E. (2009). Fathers' parenting, adverse life events, and adolescents' emotional and eating disorder symptoms: the role of emotion regulation. European Child $\mathcal{E}$ Adolescent Psychiatry. 18(4), 206-216. doi: 10.1007/s00787-008-0719-3.

Fried-Buchalter, S. (1997). Fear of succes, fear of failure, and the imposter phenomenon among male dan female marketing manager. Sex Roles: A Journal of Research. Desember,1997

Gallo, I. S., McCulloch, K. C., Keil, A., Rockstroh, B., Gollwitzer, P. M. (2009). Strategic automation of emotion regulation. Journal of 
Personality and Social Psychology. American Psychological Association. doi: $10.1037 / \mathrm{a} 0013460$.

Gullone, E. (2000). The development of normal fear: A century of research. Clinical Psychology Review, 20, 429 451. doi: 10.1016/S0272-7358(99) 00034-3.

Gullotta, T. P., Adams, G. R. (2005). Handbook of adolescent behavioral problems evidence-based approaches to prevention and treatment. New York: Springer Science Business Media, Inc.

Gross, J. J., \& Thompson, R. A. (2007). Emotion regulation: Conceptual foundations. In J .J. Gross (Ed.), Handbook of emotion regulation (pp. 324). New York: Guilford.

Gyurak, A., Gross, J. J., \& Etkin, A. (2011). Explicit and implicit emotion regulation: A dual-process framework. Journal cognition and emotion. 25(3), 400-412. doi: 10.1080 02699931.2010.544160.

Herts, K. L., McLaughlin. K. A., \& Hatzenbuehler, M. L. (2012). Emotion dysregulation as a mechanism linking stress exposure to adolescent aggressive behavior. Journal Abnorm Child Psychology, 40, 1111-1122. doi 10.1007/s10802-012-9629-4.

Hughes, E. K., Gullone, E., Dudley, A., Tonge, B. (2010). A case-control study of emotion regulation and school refusal in children and adolescents. Journal of Early Adolescence. 30(5) 691706. doi: $10.1177 / 0272431609341049$.

Lazarus, R. S. (1991). Emotion and adaptation. New York: Oxford University Press.

Li, H. \& Zhang, Y. (2008). Factors predicting rural chinese adolescents' anxieties. school psychology international. School Psychology International. 29(3), 376-384. doi: 10.11770143034308093676.
Linehan, M. M. (1993). Cognitive-behavioral treatment of borderline personality disorder. Diagnosis and treatment of mental disorders. New York: NY: Guilford Press.

Manz, C. C. (2007). Emotional disiplines: Langkah menata emosi untuk merasa lebih baik setiap hari. Jakarta: Gramedia Pustaka Utama.

Michalcakova, R., Lacinova, L., Kyonkova, H., Bousa, O., \& Jelinek, M., (2013). Fears in Czech adolescents: A longitudinal study. Journal of Early Adolescence, 33(8), 1072-1090.

Monks, F. J., Knoers, A. M., \& Haditono, S. R. (2001). Psikologi perkembangan: Pengantar dalam berbagai bagiannya. Yogyakarta: Gadjah Mada University Press.

Morris, A. S., Silk, J. S., \& Steinberg, L. (2003). Adolescents' regulation in daily life: Links to depressive symptom and problem behavior. Child Development, 74(6), 1869-1880.

Owen, P. (1998). Fears of hispanic and anglo children: Real-world fears in the 1990s. Hispanic Journal of Behavioral Sciences, 20, 483-491. doi: 10.1177/07399863980204005.

Rathus, J. H. \& Miller, A. L. (2015). DBT skill manual for adolescents. New York: Guilford.

Rice, V. J., Vu, T., Butler, J., Marra, D., Merullo, D., \& Banderet, L. (2009). Fear of failure: Implications for military health care specialist. student training. Journal of Prevention, Assessment \& Rehabilitation, 34, 465474.

Rusk, N., Tamir, M., dan Tothbaum, F. (2011). Performance and learning goals for emotion regulation. Motiv Emot, 35, 444-460. doi: 10.1007/ s11031-011-9229-6.

Russel, J. D., \& Johanningsmeier, K. A. (1981). Improving competence through 
modular instruction. USA: Kendall/ Hunt Publishing Company.

Saarni, C. (1997). Coping with aversive feelings. Motivation and Emotion, 21, 45-63. doi: 10.1007/s11031-011-9229-6.

Sagar, S. S., Lavallee, D., \& Spray, C. M. (2007). Why young elite athletes fear failure: Consequences of failure. Journal of Sports Sciences, 25, 11711184.

Sagar, S. S., Lavallee, D., \& Spray, C. M. (2009). Coping with the effects of fear of failure: a preliminary investigation of young elite athletes. Journal of Clinical Sposrts Psychology, 3, 73-98.

Santrock, J. W. (2002). Life-span development: Perkembangan masa hidup (edisi kelima). (Penerj. Achmad Chusairi, Juda Damanik; Ed. Herman Sinaga, Yati Sumiharti). Jakarta: Erlangga.

Shadish, W. R., Cook, T. D., \& Campbell, D. T. (2002). Quasi experimentation design and analysis issue for field settings. Boston: Houghton Mifflin.

Sugiyono. (2015). Metode penelitian pendidikan (pendekatan kuantitatif, kualitatif dan RED). Bandung: Alfabeta.

Thompson, R. A. (1994). Emotion regulation: A theme in search o $f$ definition. In N. A. Fox (Ed.), Monographs of the society for research in child development, 59, (2-3, serial No. 240, pp. 25-52). Chicago: University of Chicago Press.

Tirta, I. (2013, Mei). Takut tak lulus ujian nasional, Fanny gantung diri. Tempo. Retrivied from https://m.tempo.co/ read/news/2013/05/18/064481412/taku t-tak-lulus-ujian-nasional-fanny-gant ung-diri

Tugade, M. M., \& Fredrickson. (2007). Regulation of postive emotion: Emotion regulation strategies that promote resiliensce. Journal of
Happiness Studies, 8, 311-333. doi: 10. 1007/s10902-006-9015-4.

Tyson, D. F., Linnenbrink-Garcia, L., \& Hill, N. E. (2009). Regulating debilitating emotions in the context of performance: Achievement goal orientation, achieve-ment-elicited emotion, and socialization context. Human Development, 52, 329-356.

Henderson, V. L., \& Dweck, C. S. (1990). Motivation and achievement. In S. S. Feldman \& G. R. Elliott (Eds.), At the threshold: The developing adolescent (pp. 308-329). Cambridge, MA, US: Harvard University Press.

Wante, L., Mezuli, A., Van Baveren, M-L., \& Braet, C. (2016). The mediating effect of adaptive and maladaptive emotion regulation strategies on executive functioning impairment and depressive symptoms among adolescents. Journal Child Neuropsychology, 23(8), 935-953. doi: $\underline{10.1080 / 09297049.2016 .1212986}$

Wiramihardja, S. A. (2005). Pengantar psikologi abnormal. Bandung: PT. Refika Aditama. 